\title{
Casting an ergonomic eye on university libraries
}

\author{
Nicole Ferrer ${ }^{\mathrm{a}}$ and Vilma Villarouco ${ }^{\mathrm{b}}$ \\ ${ }^{a}$ Graduate Student in Architecture, UFPE, Pernambuco, Brazil \\ ${ }^{b}$ Doctor, Professor at Federal University of Pernambuco, Recife, Pernambuco, Brazil
}

\begin{abstract}
Research in the field of Ergonomics of the Built Environment has been developed with a view to consolidating studies in this area, the objective of which is to provide evidence that the joint participation of users and designers on drawing up projects is important. In this context, the theme of this study is to investigate the interactions between users and the environment in a university library. To do so, well-established techniques from Ergonomics, Architecture and Environmental Psychology were used to make a functional and behavioral evaluation to identify the level of user satisfaction in six libraries in the various study centers of the Federal University of Pernambuco in Recife, northeast Brazil, so as to identify the strengths and also weaknesses in these spatial structures.
\end{abstract}

Keywords: environmental ergonomics, ergonomics in libraries, university libraries.

\section{Introduction}

Considered as a field of knowledge of great importance in studies of the environment, the Ergonomics of the Built Environment (EBE) provides a means to think through the design of a project by foreseeing how it will be used, based on an appropriate mix of conditioning factors. These may be physical, cognitive, anthropometric, to do with accessibility, and psycho-social and cultural. The objective is to identify variables that are liable to not being met by the product proposed [1].

Since university libraries are linked to an educational institution, they are associated with the production and dissemination of knowledge. Russo corroborates this when he states that "it is considered as a segment of vital importance in the structure of the institution since its character is to promote access and the dissemination of information so that the university's objectives are fully achieved" [2].

The activities undertaken by library users are influenced by several factors, with greater or lesser intensity, such as the number of access points, physical and aspects of information and communication. Therefore, the interaction between the human-taskenvironment system occurs in all the physical, psy- chosocial and organizational variables and the ${ }^{*} \mathrm{EBE}$ plays an important role in the design of these spaces.

The planning of the physical space of libraries, under the vision of ergonomics, is not restricted to the design of effective environments as to the functional needs of users, but also embraces understanding their formal and aesthetic needs in order to provide them with a pleasant and pleasurable space and a feeling of well-being.

Therefore, this studies sets out to contribute to improving the libraries of the Federal University of Pernambuco (UFPE) in Recife, a city in the Northeast of Brazil, based on understanding the relationship between these spaces and their users by means of a specific ergonomic methodology that addresses the built environment.

\section{Method}

This study was conducted by applying the Ergonomic Methodology for the Built Environment EMBE [3], which consists of an ergonomic evaluation developed in two general stages: the first of a physical order and the second of a perceptual order.

\footnotetext{
*Corresponding author. E-mail: nicferrer@hotmail.com
} 
During the physical assessment phase, this methodology is divided into three distinct stages. Initially, a Global Analysis of the Environment is made, which is the first contact with the space, during which one should try to understand the environment and the activities carried out in it, and, in addition, the main problems and demands are characterized, which may indicate the need for intervention.

Later, during the Identification of the Environmental Configuration phase, all the physical environmental conditioning factors are identified. A survey of all environmental data is attributed to this phase, such as dimensioning, lighting, ventilation, noise, temperature, layout, movements from place to place, cladding materials and states of accessibility, which gives rise to initial hypotheses about the question of the influences of the space on the work activities to be undertaken therein.

In the third and last stage of a physical order, the Evaluation of the Environment in Use, observing the environmental in action is tackled with a view to identifying its usability, i.e. the extent to which it acts as a facilitator to or hinders the activities it harbours being undertaken.

For the stage of a perceptual order, it is necessary to insert environmental psychology, or environmental perception into the studies. In this stage, there is the need to adopt supplementary aids so as to identify variables of a more cognitive and perceptual order. The use of one of these tools helps the researcher to understand the perceptions that employees have in relation to the work spaces. From these data, a check is made on which factors are the ones most strongly linked to the motivational aspects [4].

After collecting these data, there is a need to collate all the variables so that, after a thorough analysis, an Ergonomic Diagnosis may be conducted. After the diagnosis, one moves on to the Ergonomic Recommendations, in an attempt to resolve the barriers of the space which make it difficult to perform the activities that are to be performed in it.

\section{Results}

This research study was conducted in the six largest and most used libraries in the Federal University of Pernambuco (UFPE) in Recife. They each have a varied collection that serves the wide array of courses offered by the university in various centers on campus.

\subsection{Physical arrangment}

The space set aside for each library was designed to house the functions inherent in this type of environment. However, after the centers grew because new courses were created, the amount of material increased and so did the demand for spaces to study in. These are needs from the growing number of students, which cause the limits of the libraries' dimensions to begin to be affected because of the high volume of use.

With a view to standardizing the parameters of analysis in the different units, it was possible to determine that the main activities of this space are: the area for studying in, borrowing material and technical processing. These, characterize and give purpose to this built environment, and define it in such a way that without them, the operation of the library becomes unsatisfactory. Thus, analysis of the libraries focused on these areas.

Thus, it was noted that the designs in terms of the dimensions they set are appropriate for the basic functions of a library. However, they do not support a possible expansion of the collection, or an increase in demand from users to occupy the study areas. Thus, the areas for individual study are shown currently to be unpleasant places to remain in, both because of their furnishings and their location in the environment.

From the point of view of workflows, it is noticeable that the spaces generate great difficulties as to arriving at the places where activities are performed. However, they are suitable for undertaking these activities since they are normally focal activities, which do not require a lot of movement in the space.

The activity that requires the largest amount of moving around is collecting in volumes from the archives that are left on the study as per the request of the library staff so that books are not organized incorrectly on the shelving. To do this, a trolley is used to collect books from the tables and the service counter (return of books borrowed) and the staff member in charge of this task puts the books back in their proper places. Due to the circulation flow being small, the trolleys carts are normally left at the beginning of these corridors and the books are carried in the staff member's arms the rest of the way.

Thus, in analyzing the patterns of comfort of the space in relation to layout needed to perform the work, the need is seen for a better match between the number and arrangement of fixtures in the spaces. 
They should satisfy the varied activities carried out in them, and take into account the increasing demand for space. With the current organization, the subdimensioning for the existing activities and the number of active users is identified.

\subsection{Environmental comfort}

The adverse environmental conditions that can cause discomfort, increase the risk of accidents and cause considerable damage to health are a great source of stress at work.

To check the levels of lighting comfort of the libraries, 10 to 14 points of measurement were marked in the different spaces used by those frequenting the libraries. The number of points varied in relation to the size of the building, the values of the measurements being obtained from instruments supported on the surfaces of the field of work. When there is no such surface, measurements are taken with reference to a horizontal plane $0.75 \mathrm{~m}$ above the floor.

The measurements were taken with a digital light meter in the morning (9:00), in the afternoon (15:00) and in the evening (19:00). The results were compared to the Brazilian standard NBR 5413 [5], which lays down illuminance of 100 lux in the entrance lobby, 500 lux at the service counters, 300 lux for the area of the collection, and 500 lux for study and reading rooms.

The acoustic comfort conditions were analyzed using measurements of internal noise, with a measurement being taken in the morning (9:00) and in the afternoon $(15: 00)$, the evening measurement being dispensed with on account of the sharp decline of users in this period. In order to ascertain whether the results were adequate, they were compared with the rates considered acceptable by Brazilian Standard NBR 10152 [6], which lays down that the acceptable index for libraries is between 35 and $45 \mathrm{~dB}(\mathrm{~A})$, the noise level being measured with a digital sound level meter.

The areas of the collection were excluded from the acoustic measurements, since the user spends very little time in this area in an assertive activity and one that does not require concentration or great mental effort. Thus, the noises heard there do not hinder the task at hand. Noise measurements were therefore taken in the main areas of the libraries, namely the entrance lobby, the loans counter, the individual study area and reading areas.
When making an analysis of the measurement tables, it is seen that, in most instances, the levels are not in accordance with the standard suggested by the Brazilian Association of Technical Standards ABNT (in Portuguese). There are few spaces that match up to the recommended levels, by virtue of the activities performed in them, which could cause interference in the performance of tasks and problems of a physiological order.

What is shown to be extremely necessary is a better analysis as to configuring the layout, especially with regard to the question of illumination and the creation of shadows in all the libraries. Moreover, it is noticeable that a review of the activities undertaken in each area is lacking, with a view to optimizing them in accordance with the distribution of the sectors of the library.

\subsection{Furnishings}

According to Iida [7], the ergonomic focus on the work-station tends to develop furnishings that reduce the biomechanical requirements, by seeking to put people in a good working posture, objects within the ranges of body movements and that it is easy to see information. In other words, the furnishings should involve the user as if he/she were dressed in a welladapted "outfit", in which he/she can get the job done in comfort, efficiently and safely.

In this study, the analyzes are concentrated on the furnishings of the two large areas of the library: the collection and the areas set aside for study (reading areas and individual study booths).

In the collection, the big problem with the shelves lies in the difficulty that users have when trying to reach books on the highest shelves and the recurrent postural discomfort from making a search through the shelves near the floor. The difficulty of reading the volumes because shadows are created does not happen due to the design of the racks, but rather from their poor positioning as to the points of light in the space.

As the racks are metallic, they vary in the different libraries, and may be in cream or gray colors. The collections with cream shelves appear to be better lit, though both suffer the same problem of shadows being created. This happens due to the lighter tone of the material, which creates a greater feeling of lightness in space. 
In the reading areas, the group study tables are spacious $(1.0 \times 2.0 \mathrm{~m})$ and can seat up to 6 people comfortably. In all the libraries they have the same configuration, except in the library of the Center for Natural and Exact Sciences (CCEN in Portuguese), which still has old, round tables to 6 people and finished in wood of dark shades. In a poorly lit space, where the floor is black and there is dark film on all windows, these tables help the feeling of a dark and closed space, which makes it impossible for users to feel comfort or peace of mind while undertaking their activities.

Since they are more inviting than the individual study booths, in all libraries, the group study tables end up attracting solitary users, who go on to do their activities in a space where the increase in the noise level because of conversations reach unwanted and disturbing levels.

As to the individual study areas the situations are very varied. There is no standard design for this furniture, the design of the booths is different in each library and all are inadequate, either because the work-station itself creates shadows, there is little support surface space or its poor location in space.

\subsection{Aesthetics}

Given that the space of the library houses activities that require a certain level of concentration and silence, prompting of interaction between people is not desirable and is therefore discouraged. However, the physical proximity between the different environments and even the lack of at least psychological barriers between the spaces, promotes interference in the activities, especially in the question of noise.

An example of this is the proximity of the reading area of the library of the Center for Arts and Communication (CAC), a space designed for reading and study activities, with the service counter. In this, there is a dialogue between the user and the librarian in undertaking the tasks and between the employees themselves who talk to each other while they work.

This occurrence is very commonplace in all libraries on the campus where the libraries can be characterized as having in common a high-ceilinged wide space with few partitions that best bound the different environments.

\subsection{Accessibility}

When one deals with the accessibility of a space, it is important to identify and understand the elements that prevent or restrict the perception, understanding, circulation or appropriation of the spaces by users. These obstacles are called barriers, and go beyond the meaning of mere "physical barriers", and can be classified as socio-cultural, physical and information barriers [8].

For this study, the focus will be on the physical barriers that, according to Bins Ely, Dischinger and Mattos [8], are the obstacles of architectonic origin or of the design of equipment and products that impede the autonomous access of a user.

Because of architectonic and construction standards, there are no large barriers in most libraries. However, one starts to analyze the built environment in more detail, it is seen that care was not taken to organize the library as a large ensemble, in which the architectonic design and layout make a universal design possible. Such a view is necessary, since it provides for serving the widest range of variations in anthropometric and sensory characteristics of the population, besides the constraints and deficiencies, so that all users can follow a safe and barrier-free route [9].

Instead, the design is restricted to the more conscious layout of the route that goes from the entrance to the service counter. This route has tactile flooring, as it is a floor characterized by the differentiation of texture with respect to the adjacent floor, and intended to form an alert or guideline, perceptible to visually impaired people [9]. However, as happens in the libraries of the Centre for Applied Social Sciences (CCSA in Portuguese), the route with this tactile floor heads nowhere, and ends at a part of the service counter that does not have a workstation for the librarians, which makes it difficult to attend to and creates constraints in attending to visually impaired users.

The only libraries on the Recife campus that require a more detailed analysis of the barriers in the space are the libraries of the Center for Art and Communication (CAC) and the Center for Technology and Geoscience (CTG).

So as to understand the architectonic structure of the CAC library, one sees that it has a set of levels, creating a kind of set of "half-floors" with $1.0 \mathrm{~m}$ difference between them. Thus, it is necessary to create stairs and ramps that allow free access to all the environments. However, although locomotion 
through the space is possible, all ramps and stairs are in some respect not compliant with the specific norm for accessibility in Brazil, NBR 9.050, 2004, and this jeopardizes the safety of the user.

In the case of the CTG, the isolated building which contains the library is spacious and does not cause major problems of route constriction because of the layout. However, the building has two floors, of which the upper one is designed for group study rooms and the area for individual study. The only form of access to this floor is by stairs. There is no elevator or equivalent equipment, which would allow access for wheelchair users and users with low mobility, thus segregating the entry into this space of the built environment.

\subsection{User's perception}

The search to understand the user's perception about the space, appears as a fundamental step in ergonomic evaluation. There are several possibilities in this field that has several analysis tools. This study used the Constellation of Attributes, idealized by Moles [10] and later studied by several researchers at the Strasbourg Institute of Social Psychology, including Ekambi-Schmidt [11]. It aims to assist professionals linked to the design area in order to make them knowledgeable about the psychological consciousness of the user vis-à-vis space.

Analyses of the spontaneous associations of ideas were conducted, and sought to identify the perception that users have in relation to the spaces, based on the images used by people to describe or characterize the environment in which they live.

This allows, as per Schmidt [4], a separation of the stereotyped image of an area from their subjective image. It consists of an experimental technique, allowing a perfectly readable graphical representation of the data, which are organized in a concise and ranked way. This form of representation allows the behavior of the attributes to be evaluated in relation to the space evaluated.

The tool enables the analysis of two spheres of the built environment: the conceptualization of the ideal space, with the association of ideas directed towards spontaneous characteristics; and the other one that defines real space, with the association of ideas based on induced characteristics.

The questionnaires were administered on 20 people in each of the libraries on the Recife campus of the Universidade Federal de Pernambuco, of whom 15 respondents were users who had the habit of going to the library regularly and 05 were librarians on the staff. In all, four graphs per library were drawn, a total of 24 Constellations of Attributes for analysis.

Thus, for the construction of the Imaginary Constellation of Attributes (Figure 1), which refers back to the idealization of the space, the following question is made: "When you think of a library, in general, what ideas or images come to mind?", thus making it possible to evaluate the symbolic image of the individual vis-à-vis the environment.

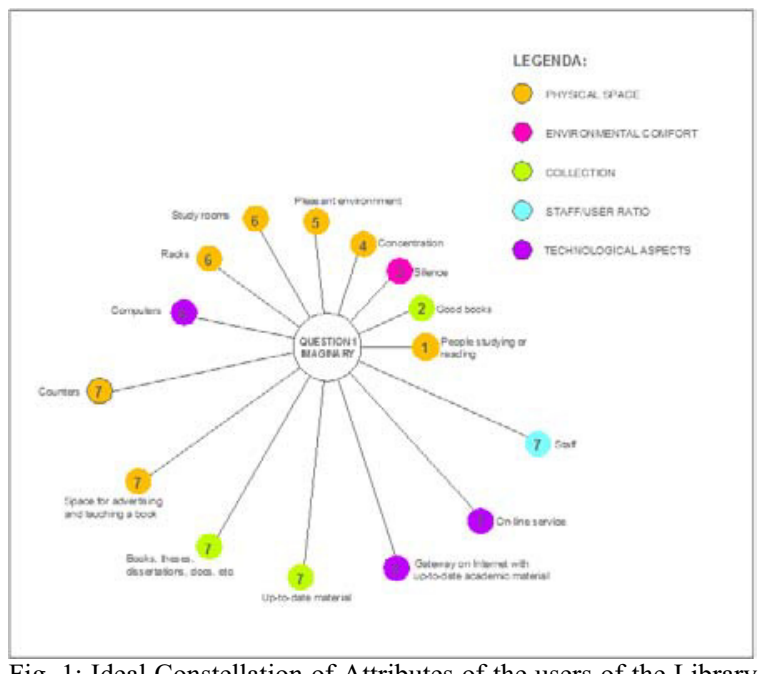

of the Centre of Education (CE)
ig. Ideal Constellation of Attil

Now, for the construction of the Constellation of Real Attributes (Figure 2), which allows concrete visualization of the environment, the same respondents were asked: "When you think of this library, what ideas or images come to mind?", which allows the dissociation of the idea of affection that the user may have towards the space he/she occupies, which permits a more methodical analysis of the object under study. These questions aim to distinguish what is objective from what is subjective in the user's perception. 


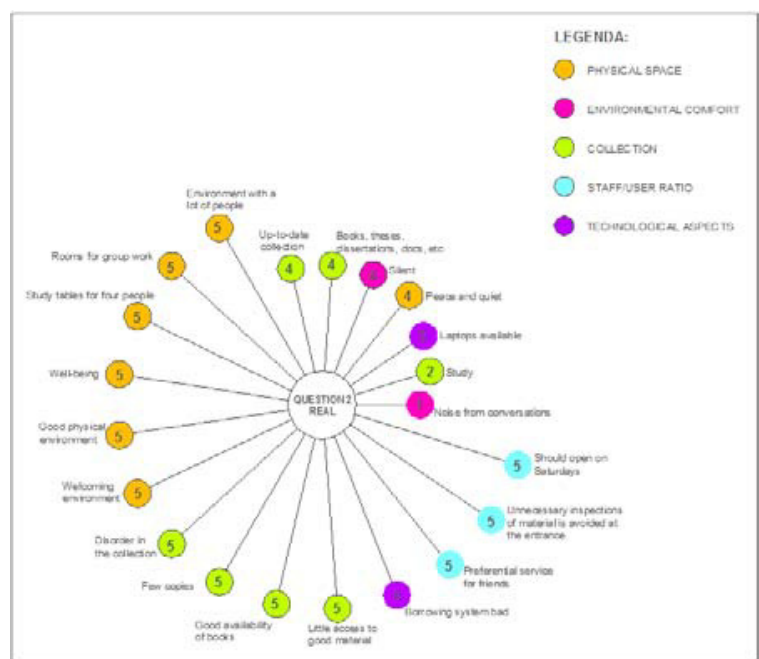

Fig. 2: Constellation of real attributes of the users of the Library of the Centre of Education (CE)

\section{Discussion}

After conducting assessments and diagnoses of all the libraries, the constancy of the problems encountered, which are repeated in a similar way, is noticeable. In relation to the physical arrangement, it is clear that the built environment can no longer bear the ever-increasing user demand, which makes it impossible to perform tasks more smoothly, without large physical and psychological barriers. Another major problem lies in the unsuitability of including tasks that should be performed in them, thus not providing the user with a comfortable environment that encourages and optimizes their activities.

When doing an analysis of the values found with the measurement of luminous comfort, one notices that for the most part the points are not in accordance with the norm suggested by the Brazilian Association of Technical Norms - ABNT. There are few spaces that match the need for illuminance based on the activity performed in them, which can cause interference in the performance of tasks. It was noticed that greater care has not been taken with the lighting project, mainly because of the absence of matching the suitability in the positioning of the lamps with the layout, causing the emergence of large shadows that darken the work surface. Another common problem, and one which can be easily solved, is the ability of the light bulbs themselves to emit and supply luminosity in spaces with very high ceilings, in large spans, this kind of space being characteristic of the libraries of UFPE.
The average noise level is well above the range of 35 to $45 \mathrm{~dB}$ suggested by the Brazilian norm, and is in the margin of 55 to $65 \mathrm{~dB}$. Given that the spaces of the libraries are single large spans, the propagation of sound through this environment is easier. Since the service counters are next to the tables of the reading areas, the conversations that happen in this place, and very often the very sound of the machine that issues a receipt for borrowed material, causes a distraction for those users who are trying to concentrate on their studies and readings. Also the fact of thinking of individual study at tables with four to six seats is inadequate. This furniture tends to attract study groups, who in most cases talk without being aware that they are disturbing a user at the next table.

The environmental comfort questionnaires point in the direction that users do not manage to have the due perception of the inadequacy of the environment, if the ABNT norms are taken as taken as the basis

A major impediment to the libraries is the fact that the built environment does not make it possible to facilitate the tasks of studying and reading, which comprise the main activities performed in the space. There is no separation of the areas, which creates a very large permeability between the different environments, thus interfering with the various tasks that are performed simultaneously.

Thus, it is understood the need for a reassessment of the architectonic standards that characterize a university library. There is a need to see to it that users consider this space as an environment to stay in, where different activities are carried out, and not as a depository space of the object of reading, in which one merely borrows the material that one needs.

\section{References}

[1] Villarouco, Vilma. Avaliação Ergonômica do projeto arquitetônico. In: XII Congresso Brasileiro de Ergonomia VI Congresso Latino-Americano De Ergonomia e I Seminário Brasileiro de Acessibilidade Integral. Recife, 2002. Anais

[2] Russo, Mariza. Financiamento para bibliotecas universitárias brasileiras. In: $\mathrm{X}$ Seminário Nacional de Bibliotecas Universitárias - X SNBU. Anais... UFC, 1998.

[3] Villarouco, V. An ergonomic look at the work environment, Proceedings of IEA 09: 17 ${ }^{\text {th }}$ World Congress on Ergonomics. China: Beijing. 2009.

[4] Andreto, L. F. M. Influência do espaço construído na produtividade: Avaliação baseada na ergonomia do ambiente construído e na psicologia dos espaços de trabalho. Dissertação. PPGEP-UFPE, Recife, 2005.

[5] Associação Brasileira de Normas Técnicas. NBR 5.413: Iluminância de interiores. Rio de Janeiro, 1992.

[6] Associação Brasileira de Normas Técnicas. NBR 9.050: Acessibilidade de pessoas portadoras de deficiências a 
edificações, espaço, mobiliário e equipamentos urbanos. Rio de Janeiro, 1997.

[7] Iida, Itiro. Ergonomia: projeto e produção. São Paulo: Edgar Blucher, 2001

[8] Bins Ely, V. H. M. Dischinger, M. Mattos, M. L. Sistemas de Informação Ambiental - Elementos indispensáveis para acessibilidade e orientabilidade. Anais do ABERGO 2002 VI Congresso Latino-Americano de Ergonomia e XII Congresso de Ergonomia. Recife, 2002.
[9] Associação Brasileira de Normas Técnicas. NBR 9.050: Acessibilidade de pessoas portadoras de deficiências a edificações, espaço, mobiliário e equipamentos urbanos. Rio de Janeiro, 1997.

[10]Moles, A. Sociodinámica de la cultura. Barcelona: Editora G. Gili, 1968.

[11] Schmidt, J. E. La percepción Del hábitat. Barcelona, G. Gili, 1974. 